\title{
De Novo ring chromosome 11 and non-reciprocal translocation of 11 p15.3-pter to 21 qter in a patient with congenital heart disease
}

Ying Peng ${ }^{1}$, Ruiyu Ma ${ }^{1}$, Yingjie Zhou ${ }^{2}$, Yan Xia', Juan Wen', Yanghui Zhang ${ }^{1}$, Ruolan Guo ${ }^{1}$, Haoxian Li', Qian Pan' , Rui Zhang ${ }^{1}$, Chengyuan Tang ${ }^{3}$, Desheng Liang ${ }^{1}$ and Lingqian $\mathrm{Wu}^{1 *}$

\begin{abstract}
Background: Ring chromosome $11[\mathrm{r}(11)]$ is a rare chromosomal abnormality that forms when both arms of chromosome 11 break, and then reunite with each other. Once a ring chromosome forms, the distal ends of both arms of the chromosome are usually lost.

Case Presentation: We reported a 12 years old girl patient with congenital heart disease and distinctive facial features. Cytogenetic and molecular analyses using standard G-banding, fluorescence in situ hybridization and Single nucleotide polymorphism array were performed to identify genetic causes in the patient.

The patient carried r(11)(p15.3q24.1) and 11p15.3-pter non-reciprocal translocation to 21qter, accompanied with 8.9 $\mathrm{Mb}$ deletion of 11q24.2q25. A literature review was performed to establish genotype-phenotype correlations of the $\mathrm{r}(11)$ and $11 \mathrm{q}$ terminal deletion syndrome.

Conclusions: To the best of our knowledge, this is the first case of non-reciprocal translocation with a terminal deletion in $r(11)$. These findings provide important information for genetic counseling for this family, and may improve our understanding of the genotype-phenotype correlation of ring chromosome 11 disorders.
\end{abstract}

Keywords: Ring chromosome 11, Non-reciprocal translocation, Congenital heart disease, 11q terminal deletions

\section{Background}

Ring chromosomes are uncommon cytogenetic abnormalities that have been implicated in all human chromosomes, especially in chromosome 1, 8, 15, X, Y (http:// ssmc-tl.com/sSMC.html). Ring chromosomes are formed when both chromosome arms break and then reunite a continuous ring, which is usually accompanied with the loss of some genetic materials [1] Complete ring chromosomes with no apparent deletion of the telomeric ends have aslo been implicated [2]. The clinical manifestations of patients with ring chromosome may be highly variable, which are influenced by many factors, including the loss of genomic materials, the structural instability

\footnotetext{
* Correspondence: wulingqian@sklmg.edu.cn

${ }^{1}$ State Key Laboratory of Medical Genetics, Central South University, 110 Xiangya Rd., Changsha, Hunan 410078, China

Full list of author information is available at the end of the article
}

of rings at mitosis, the rate of secondary aneuploidy cell [1, 3-5].

Ring chromosome $11[\mathrm{r}(11)]$ is quite rare. Since the first report by Valente M et al. in 1997, only 19 cases of $r(11)$ have been reported [6-16]. Except for two familial $r(11)$ cases [6, 14], the others are sporadic. Difference in clinical features was described among patients carrying $\mathrm{r}(11)$, but most cases showed short stature, microcephaly, growth delay, and mental retardation. Most r(11) cases were determined by conventional cytogenetic analysis, molecular analysis was performed in only two reports $[6,16]$, so precise genotype-phenotype correlations for $r$ (11) remains largely unknown.

We report here a patient carried $\mathrm{r}(11)(\mathrm{p} 15.3 \mathrm{q} 24.1)$ and 11p15.3-pter non-reciprocal translocation to 21qter, accompanied with $8.9 \mathrm{Mb}$ deletion of $11 \mathrm{q} 24.2 \mathrm{q} 25$. To the 
best of our knowledge, this is the first case of nonreciprocal translocation with a terminal deletion in $\mathrm{r}$ (11).

\section{Case presentation \\ Patient}

The proband, a girl of 12 years old, was the first child of healthy non-consanguineous parents. Her father and mother were 30 and 28 years old at her birth, respectively. After uneventful and full-term pregnancy, the baby was delivered by cesarean section with a birth weight of $2500 \mathrm{~g}$, length $50 \mathrm{~cm}$ and head circumference $34.5 \mathrm{~cm}$. Her mother contacted toxic substance mercury during pregnancy. In the neonatal period, the girl was diagnosed with Tetralogy of Fallot, a congenital heart defect. The girl had no pathological jaundice. She could lift her head from a prone position at 3 months, walked at 14 months, and spoke at 15 months. At 2 years old, she underwent surgery to treat heart disease.

The patient was fully investigated when she was referred to our clinic genetics at the age of 12 years. Her height was $145 \mathrm{~cm}$ ( $\sim 50$ th centile), weight $55 \mathrm{~kg}$ ( 90th centile). She had several dysmorphic features, including facial asymmetry, high prominent forehead, small eyes, ocular hypertelorism with droopy eyelids, epicanthal folds, flat nasal bridge, thin upper lip, short neck, broad thorax, small hands and feet, the fifth finger bent and brachydactyly. There were white spots on her arms and legs. Her language skills were satisfactory, and her motor development was normal. Behavioral problems were noticed, including a short attention span, easy distractibility, and inactive communication with others. The Raven's Standard Progressive Matrices revealed that her intelligence quotient (IQ) was 72. Platelet counts on presentation was $102 \times 10^{9} / \mathrm{L}$, which is within normal limits. Platelet morphology with peripheral smear showed no giant platelets or any other abnormality (Fig. 1).

\section{Cytogenetic and molecular analyses}

G-banding (400-550bands) was performed on metaphase chromosomes of cultured peripheral blood lymphocytes obtained from the patient and her parents. FISH analysis was performed according to the manufacturer's instruction (www.abbottmolecular.com), and the images were captured using a Leica DM500B camera and Leica CW400 software (Applied Imaging). Three bacterial artificial chromosome (BAC) clone probes specific for the region 11p15.4 (RP11-89B9, red), the 11q25 (RP11-7 K8, green), and 21q22.3 (RP11-135B17, orange) were applied. To determine the presence of telomere regions in $\mathrm{r}(11)$ and the derivative chromosome 21, FISH using telomere region-specific probes Mix \#4 and Mix \#11 (Vysis ToTelVysion Multi-Color FISH probe, Abbott, U.S.) was performed. Mix \#4 contains specific probes for 4p(chr4: 86938, Spectrum Green), 4q(chr4: 190049608, Spectrum Orange) and 21q(chr21: 47931911, Spectrum Green and Spectrum Orange). Mix \#11 contains specific probes for 11p(chr11: 199260, Spectrum Green), 11q(chr11: 134643494, Spectrum Orange) and 18p(chr18: 140409, Spectrum Green and Spectrum Orange).
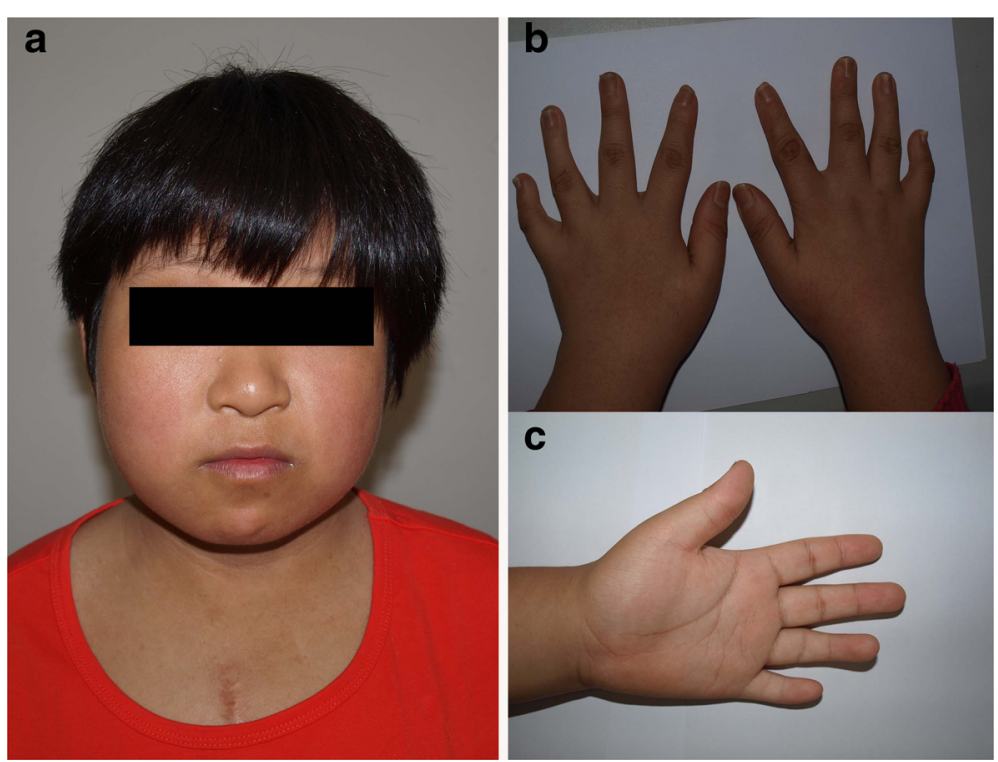

Fig. 1 The clinical features of the patient. a Frontal view of the patient, showing facial asymmetry, high prominent forehead, small eyes, ocular hypertelorism with droopy eyelids, epicanthal folds, flat nasal bridge, thin upper lip, short neck, and broad thorax. b, c Small hands, the fifth finger bending and brachydactyly 
Genomic DNA was extracted from peripheral blood lymphocytes of the patient using the phenol-chloroform method. Genome-wide copy number analysis was performed using Illumina Human Cyto-SNP12 BeadChip (Illumina, San Diego, CA). The arrays were scanned on a microarray scanner and analyzed using GenomeStudio (cnv Partition Plug-in v3.1.6) software. The operative procedures mentioned above were all performed according to the manufacturer's recommended protocols (www.illumina.com).

\section{Results}

G-banding analysis showed the karyotype of the patient was 46, XX, r(11) (p15.3q24.1), der(21) t(11;21) (p15.3; qter) [158] / 45,XX,-11 [16] / 46, XX, r(11; 11) (p15.3q24.1; p15.3q24.1), der(21) t(11;21) (p15.3;qter) [5] (Fig2. a, b, c). The karyotypes of both parents were normal (data not shown). FISH analysis further confirmed the $\mathrm{r}(11)$, the absence of 11qter signal and the translocation of 11pter signal to chromosome 21qter (Fig2. d, e). FISH analysis showed there were two telomeres in the derivative chromosome 21qter in the patient (Fig2. f). SNP array analysis detected a 8,915,290 bp deletion in 11q24.2q25 (Fig2. g). Collectively, these finding suggest that the karyotype of the patient is 46,XX,r(11)(p15.3q24.1),der(21)t $(11 ; 21)(\mathrm{p} 15.3 ; \mathrm{qter})[158]$ / 45,XX,-11[16] / 46,XX,r(11;11) (p15.3q24.1;p15.3q24.1),der(21)t(11;21)(p15.3;qter)[5]. ish r(11)(p15.3q24.1)(RP11-89B9-,RP11-7 K8-,RP11-135B17-), der(21)t(11;21)(p15.3;qter)( RP11-89B9+, RP11-135B17+). arr 11q24.2q25(126,028,717-134,944,006) $\times 1 \mathrm{dn}$.

\section{Discussion}

Ring formation and translocation in a same chromosome have been rarely described. So far, only four similar cases have been reported in the literature [17-20], none of which happens in chromosome 11. Here, we reported a special chromosomal rearrangement in a patient carrying $\mathrm{r}(11)$ and 11p15.3-pter non-reciprocal translocation to 21qter, accompanied with a terminal deletion at chromosome 11q24.2q25.

Considering this complex rearrangement derived from two different chromosomes 11 and 21,our cellular and molecular analysis suggested that the breaks might happened at two specific time points, either at the time when sister chromatids started to separate during meiosis II or before DNA replication at the interphase of mitosis just after the zygote formation. The different between them was the state of the gamete. In former situation, gamete was abnormal, which contained a $\mathrm{r}(11)$ and a der(21). In the latter situation, gamete was normal. But, no matter in which situation, the chimeric karyotype $r(11 ; 11)$ and -11 could be generated in the subsequent mitosis because of the nondisjunction of duplicate ring. When chromosome breaks take place, the broken chromosomes are highly unstable. To prevent chromosome fusion and exonucleolytic degradation, the broken

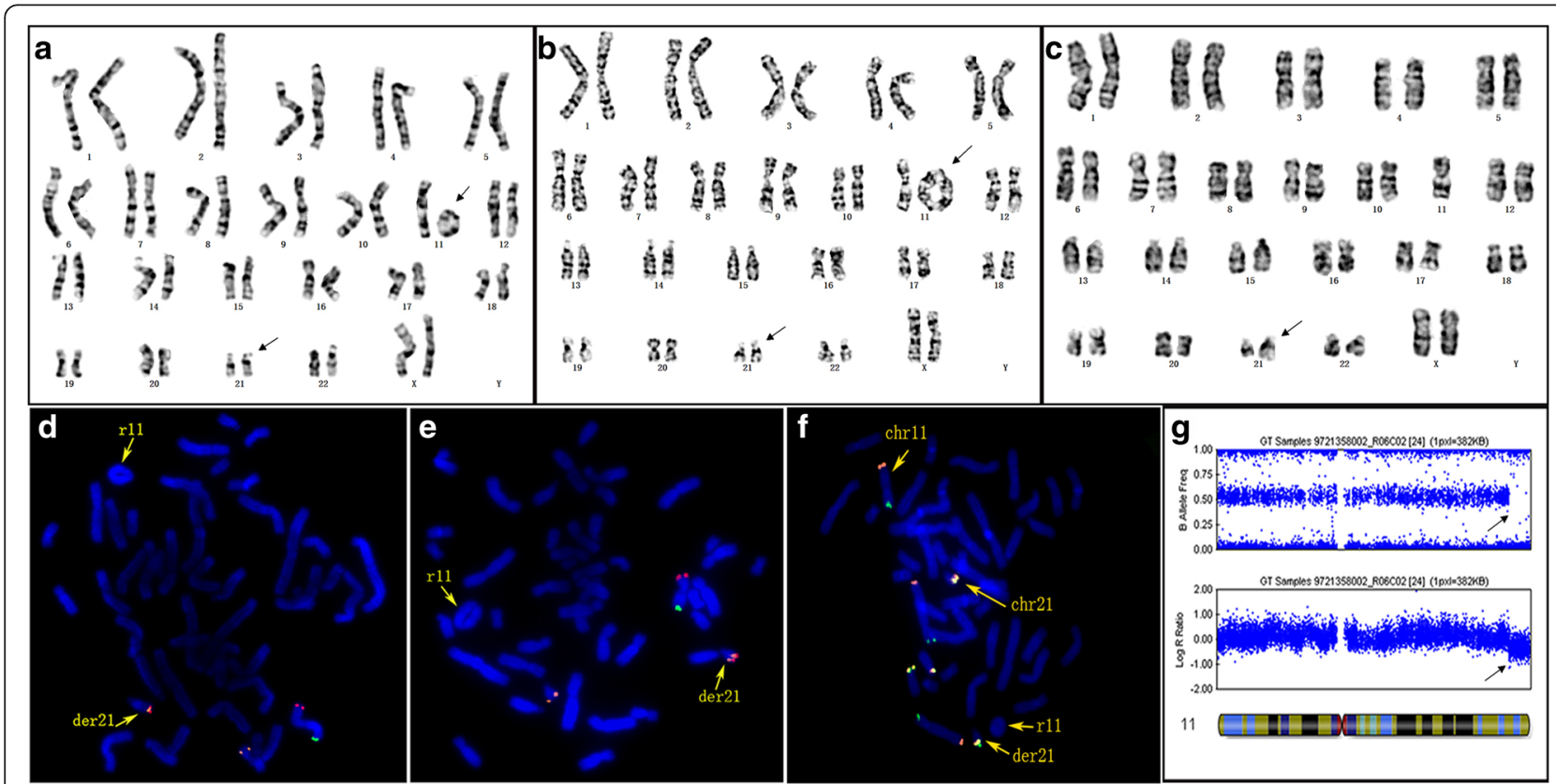

Fig. 2 Cytogenetic and molecular analysis results. a, b, c G-banding indicated chimerism of $r(11)$, r(11; 11) and -11. d, e FISH using three bacterial artificial chromosome (BAC) clone probes showed a red signal translocation to 21 qter and a green signal absent, while the two orange signals still at 21q22.3. f FISH using telomeric probes showed two telomeres presented on the derivative chromosome $21 \mathrm{q}$. $\mathbf{g}$ Copy number variation analysis for individual SNP loci along chromosome 11 showed a $8.9 \mathrm{Mb}$ deletion at 11q24.2q25 
ends are usually rescued by the addition of telomeric tandem repeat sequence at the breakpoint site or by capturing the telomeric sequences from the same or another chromosome [21, 22]. In addition to telomere healing and capture, Knijnenburg et al. [21] also suggested that ring chromosome formation acted as an alternative mechanism of chromosome rescue in response to chromosome breaks. In a word, chromosome healing has been often involved in chromosome rearrangement, but the specific mechanism remains unclear [23]. In our case, both ring chromosome formation and capturing the telomeric sequences were observed. To prevent exonucleolytic degradation, the breakpoint of chromosome $11 \mathrm{p} 15.3$ and 11q24.1 were reunited to form a ring, and the 11p15.3pter fragment recombined with telomeric sequences of 21qter possibly through nonhomologous end joining (NHEJ) that is the major form of Double-strand breaks (DSBs) repair [24].

The clinical features of our patient included facial dysmorphic features, congenital heart disease and learning difficulties, which also characterized $\mathrm{r}(11)$ or $11 \mathrm{q}$ terminal deletion syndrome. A summary of the cases of $\mathrm{r}(11)$ or $11 \mathrm{q}$ terminal deletion syndrome are listed in Table 1. Interestingly, about $70 \%$ patients with $\mathrm{r}(11)$ or 11q deletion were female. One potential reason for the phenomenon is that the expression of $11 \mathrm{q}$ terminal deletion is somehow influenced by the sex chromosome complement [25].

To narrow down potential genetic causes of the clinical features of $r(11)$ or $11 \mathrm{q}$ deletion, we compared our data of SNP array analysis with those published. The case two from Hansson et al. [6] was very close to our case. In the case two, no deletion on the short arm of chromosome 11 was noticed, and a considerable deletion region at the terminal part of the long arm of chromosome 11 was detected. The deletion of the case two was $14.1 \mathrm{Mb}$ at $11 \mathrm{q} 23.3 \mathrm{q} 25$, which contains a large number of genes, making an appropriate genotype-phenotype correlation difficult. Despite the difference in the size of deletion, both the case two and our case shared some phenotypes. The overlapping region between them encompasses 29 RefSeq genes, including some diseaserelevant genes: JAM3(OMIM:606871), ETS1(OMIM: 164720), BARX2(OMIM:604823), FLI1(OMIM:193067), NTM(OMIM:607938), KIRREL3(OMIM:607761) and B3GAT1(OMIM:151290) (Fig. 3). Phillips et al. [26] provided evidence that the JAM3 located at chromosome 11q25 was a strong candidate gene for cardiac phenotype. A crucial role of the ETS1 gene in heart development has also been reported [27]. Moreover, the haploinsufficiency of the JAM3 and ETS1 in patients with cardiac anomalies, and their deletion in our patient with congenital heart

Table 1 A comparison of clinical features between the patient of this study and those previously reported with $r(11)$ and distal del(11q) syndrome

\begin{tabular}{|c|c|c|c|}
\hline Clinical findings & r(11) (Hansson KB et al. 2012 [6]) & $\begin{array}{l}\text { Distal del(11q) syndrome } \\
\text { (Grossfeld et al. } 2004 \text { [31]) }\end{array}$ & Present patient \\
\hline Number & $n=19$ & $n=110$ & 1 \\
\hline Gender & $14 f / 5 m$ & $72 f / 38 m$ & $f$ \\
\hline Age & Ranges from prenatal to adult & Ranges from newborn to adult & 12 years \\
\hline De novo & 13 & $+/ 94 \%$ & + \\
\hline Short stature & 14 & $+/ 68 \%$ & - \\
\hline Microcephaly & 14 & N.I. & - \\
\hline Dysmorphic features & 6 & $+/ 83 \%$ & + \\
\hline Short and broad neck & N.I. & $+/ 50 \%$ & + \\
\hline Mental or development retardation & $\begin{array}{l}15 \text { range form mild to severe } \\
\text { mental retardation, }\end{array}$ & $+/ 85 \%$ & Learning difficuties \\
\hline Congenital heart defect & 5 & $+/ 56 \%$ & + \\
\hline Skin & $\begin{array}{l}13 \text { with café-au-lait spots, } \\
6 \text { of them with other pigment } \\
\text { abnormalities, } 5 \text { normal }\end{array}$ & $+/ 22 \%$ with eczama & Pigment abnormalities \\
\hline Skeletal abnormality & 1 & + & + \\
\hline Kidney abnormality & 2 Wilm's tumor & $+/ 8 \%$ & - \\
\hline Hematological abnormalities (Paris-Trousseau Syndrome) & N. A. & $+/ 94 \%$ & - \\
\hline Recurrent infections & N. A. & $+/ 54 \%$ & + \\
\hline Gastrointestinal & N. A. & $+/ 15 \%$ & - \\
\hline
\end{tabular}




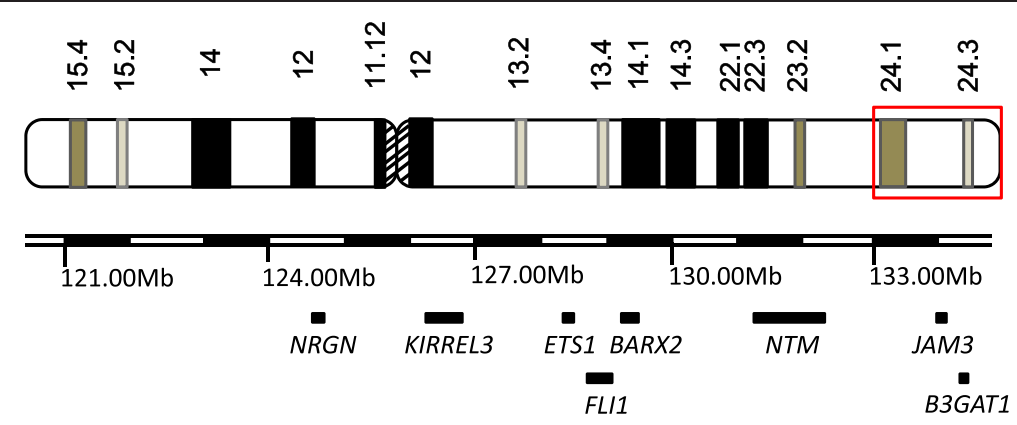

Case 2 of Hansson KB et al., 2012

Present

study

Fig. 3 The deletion region of chromosome 11 in the patient and the disease relevant genes within the region

disease reinforce the critical role of these two genes in heart development. Meech et al. [28] suggested that the $B A R X 2$, which encodes an important regulator of muscle growth and repairment, was responsible for facial dysmorphic features, which was supported by our findings. More interestingly, the case two reported by Hansson et al. had severe mental retardation, however our patients showed only some learning difficulties. Four genes within the deletion region of the case two have been associated with nervous system diseases, including NRGN(OMIM: 602350), KIRREL3, NTM and B3GAT1. Except for NRGN, the other three were also deleted in our cases. These findings suggest that NRGN may be a strong candidate gene that is responsible for the mental retardation. NRGN, which locates at 11q24.2, encodes a direct target for thyroid hormone in human brain [29]. Moreover, Ohi et al. reported a NRGN mutation in 414 Japanese patients with schizophrenia and healthy subjects [30]. They concluded that the genetic risk variant in NRGN gene may be associated with the reduction of intellectual ability. Furthermore, Grossfeld et al. concluded that at least $94 \%$ patients with 11q deletion had the Paris-Trousseau Syndrome [31], which is mainly featured by thrombocytopenia, abnormal platelet function and abnormal megakaryocytes. The proto-oncogene FLI-1, which maps at chromosome 11q24.3, plays a fundamental role in megakaryocytic differentiation. The haploinsufficiency of FLI-1 was associated with dysmegakaryocytopoiesis and thrombocytopenia. However, our patient showed no features of ParisTrousseau Syndrome, although she had the deletion of FLI-1 gene. We hypothesize that other genes on 11q24 may co-contribute to thrombocytopenia with FLI-1. In line with this notion, a recent report by Trkova et al. implicated that a second unknown hit was required to develop thrombocytopenia except for the deletion of FLI-1 gene [32]. Of course, besides the loss of genetic materials, the configuration of the ring chromosome and epigenetic factors may contribute to the phenotype through influencing gene expression [33-35]. So, these factors also needs to be taken into account in the evaluation of the genetic consequences.

\section{Conclusions}

In summary, this is the first report of $\mathrm{r}(11)$ and nonreciprocal translocation of 11p15.3-pter to 21qter, accompanied with a terminal deletion of $11 \mathrm{q} 24.2 \mathrm{q} 25$. These findings provided important information for genetic counseling and future clinical treatment for the patient, improve our understanding of the genotype-phenotype connection of $\mathrm{r}(11)$, and help further exploring the specific mechanism of chromosome rearrangement.

\section{Consent}

Written informed consent was obtained from the parents of the patient for publication of this Case report and any accompanying images. A copy of the written consent is available for review by the Editor-in-Chief of this journal.

\section{Abbreviations \\ BAC: bacterial artificial chromosome; DSBs: double-strand breaks; FISH: fluorescence in situ hybridization; NHEJ: nonhomologous end joining; $\mathrm{R}$ (11): ring chromosome 11; SNP array: single nucleotide polymorphism array.}

\section{Competing interests}

The authors declare that they have no competing interests.

\section{Authors' contributions}

YP wrote the manuscript, interpreted the SNP array results and coordinated the clinical analysis of the patient; RM was involved in SNP array analysis and helped to draft the manuscript; YZ referred the patient for study; YX and JW performed the cytogenetic and FISH studies and diagnoses; $Y Z$ and RG carried out the microarray; HL coordinated the study; $Q P, R Z, C T$ and $D L$ revised the manuscript critically for important intellectual content; LW initiated the study, made substantial contribution to conception design and revised the manuscript critically. All authors read and approved the final manuscript. 


\section{Acknowledgements}

We thank the patient and her family member for their participation in this study. Thank the Maternal and Children's Hospital of Shenzhen for providing telomere region-specific probes. The work was supported in part by grants from National Key Basic Research Program of China (2012CB944600) and National Key Technology R\&D Program of China (2012BAI09B05).

\section{Author details}

${ }^{1}$ State Key Laboratory of Medical Genetics, Central South University, 110 Xiangya Rd., Changsha, Hunan 410078, China. ${ }^{2}$ The Second Hospital of Hebei Medical University, Shijiazhuang, Hebei, P.R. China. ${ }^{3}$ Department of Nephrology, The Second Xiangya Hospital, Central South University, Changsha, Hunan, P.R. China.

Received: 11 August 2015 Accepted: 28 October 2015 Published online: 09 November 2015

\section{References}

1. Kosztolanyi G. Does "ring syndrome" exist? An analysis of 207 case reports on patients with a ring autosome. Human Genet. 1987;75(2):174-9.

2. Sigurdardottir S, Goodman BK, Rutberg J, Thomas GH, Jabs EW, Geraghty MT. Clinical, cytogenetic, and fluorescence in situ hybridization findings in two cases of "complete ring" syndrome. Am J Med Genet. 1999;87(5):384-90.

3. Cote GB, Katsantoni A, Deligeorgis D. The cytogenetic and clinical implications of a ring chromosome 2 . Annales de genetique. 1981;24(4):231-5

4. Sodre CP, Guilherme RS, Meloni VF, Brunoni D, Juliano Y, Andrade JA, et al. Ring chromosome instability evaluation in six patients with autosomal rings. Genet Mol Res: GMR. 2010;9(1):134-43.

5. Guilherme RS, Meloni VF, Kim CA, Pellegrino R, Takeno SS, Spinner NB, et al. Mechanisms of ring chromosome formation, ring instability and clinical consequences. BMC Med Genet. 2011;12:171.

6. Hansson KB, Gijsbers AC, Oostdijk W, Rehbock JJ, de Snoo F, Ruivenkamp CA, et al. Molecular and clinical characterization of patients with a ring chromosome 11. Eur J Med Genet. 2012;55(12):708-14.

7. Valente M, Muller H, Sparkes RS. Ring 11 chromosome (46, xx, r11(p15q25)) Human Genet. 1977;36(3):345-50.

8. Niikawa N, Jinno $Y$, Tomiyasu T, Fukushima $Y$, Kudo K. Ring chromosome 11 $[46, X X, r(11)(p 15 q 25)]$ associated with clinical features of the 11q-syndrome. Annales de genetique. 1981;24(3):172-5.

9. Retbi JM, Raoul O, Allemon MC, Dayras JC. [Ring-shaped chromosome 11 (46, XX, r11). A new case]. Nouv Presse Med. 1981;10(3):181.

10. Cousineau AJ, Higgins JV, Scott-Emuakpor AB, Mody G. Brief clinical report: ring-11 chromosome: phenotype-karyotype correlation with deletions of 11q. Am J Med Genet. 1983;14(1):29-35.

11. Romain DR, Gebbie OB, Parfitt RG, Columbano-Green LM, Smythe RH, Chapman CJ, et al. Two cases of ring chromosome 11. J Med Genet. 1983;20(5):380-2.

12. Daniele S, Pecorelli F, Tiepolo L, Armellini R, Liotti FS. Congenital ocular and other systemic abnormalities associated with ring-11 chromosome. Graefes Arch Clin Exp Ophthalmol. 1986;224(3):317-20.

13. Palka G, Verrotti A, Peca S, Mosca L, Lombardo G, Verrotti M, et al. Ring chromosome 11. A case report and review of the literature. Annales de genetique. 1986;29(1):55-8.

14. Fagan K, Suthers GK, Hardacre G. Ring chromosome 11 and cafe-au-lait spots. Am J Med Genet. 1988;30(4):911-6.

15. Mohamed AN, Ebrahim SA, Aatre R, Qureshi F, Jacques SM, Evans MI. Prenatal diagnosis of a de novo ring chromosome 11. Am J Med Genet. 2001;102(4):368-71.

16. Carella M, Spreafico F, Palumbo O, Storlazzi CT, Tabano S, Miozzo M, et al. Constitutional ring chromosome 11 mosaicism in a Wilms tumor patient: Cytogenetic, molecular and clinico-pathological studies. Am J Med Genet A. 2010;152A(7):1756-63.

17. Mukerjee D, Burdette WJ. Multiple congenital anomalies associated with a ring 3 chromosome and translocated $3 / X$ chromosome. Nature. 1966;212(5058):153-5.

18. Yip MY, MacKenzie H, Kovacic A, McIntosh A. Chromosome 3p23 break with ring formation and translocation of displaced 3p23->pter segment to 6pter. J Med Genet. 1996;33(9):789-92.
19. Stevens CA, Fineman RM, Breg WR, Silken AB. Report of two cases of distal deletion of the long arm of chromosome 6. Am J Med Genet. 1988;29(4):807-14.

20. Zahed L, Oreibi G, Azar C, Salti I. Ring chromosome 18q and jumping translocation 18p in an adult male with hypergonadotrophic hypogonadism. Am J Med Genet A. 2004;129A(1):25-8.

21. Knijnenburg J, van Haeringen A, Hansson KB, Lankester A, Smit MJ, Belfroid $\mathrm{RD}$, et al. Ring chromosome formation as a novel escape mechanism in patients with inverted duplication and terminal deletion. Eur J Hum Genet. 2007;15(5):548-55.

22. Wilkie AO, Lamb J, Harris PC, Finney RD, Higgs DR. A truncated human chromosome 16 associated with alpha thalassaemia is stabilized by addition of telomeric repeat (TTAGGG)n. Nature. 1990;346(6287):868-71.

23. Vermeesch JR, Falzetti D, Van Buggenhout G, Fryns JP, Marynen P. Chromosome healing of constitutional chromosome deletions studied by microdissection. Cytogenet Cell Genet. 1998;81(1):68-72.

24. Miller D, Reynolds GE, Mejia R, Stark JM, Murnane JP. Subtelomeric regions in mammalian cells are deficient in DNA double-strand break repair. DNA Repair (Amst). 2011;10(5):536-44.

25. Frank J, Riccardi VM. The 11q - syndrome. Human Genet. 1977;35(2):241-6.

26. Phillips HM, Renforth GL, Spalluto C, Hearn T, Curtis AR, Craven L, et al. Narrowing the critical region within 11q24-qter for hypoplastic left heart and identification of a candidate gene, JAM3, expressed during cardiogenesis. Genomics. 2002;79(4):475-8.

27. Ye M, Coldren C, Liang X, Mattina T, Goldmuntz E, Benson DW, et al. Deletion of ETS-1, a gene in the Jacobsen syndrome critical region, causes ventricular septal defects and abnormal ventricular morphology in mice. Hum Mol Genet. 2010;19(4):648-56.

28. Meech R, Gonzalez KN, Barro M, Gromova A, Zhuang L, Hulin JA, et al. Barx2 is expressed in satellite cells and is required for normal muscle growth and regeneration. Stem Cells. 2012;30(2):253-65.

29. Martinez de Arrieta C, Morte B, Coloma A, Bernal J. The human RC3 gene homolog, NRGN contains a thyroid hormone-responsive element located in the first intron. Endocrinology. 1999;140(1):335-43.

30. Ohi K, Hashimoto R, Yasuda Y, Fukumoto M, Yamamori H, Umeda-Yano S, et al. Influence of the NRGN gene on intellectual ability in schizophrenia. J Hum Genet. 2013;58(10):700-5.

31. Grossfeld PD, Mattina T, Lai Z, Favier R, Jones KL, Cotter F, et al. The $11 \mathrm{q}$ terminal deletion disorder: a prospective study of 110 cases. Am J Med Genet A. 2004;129A(1):51-61.

32. Trkova M, Becvarova V, Hynek M, Hnykova L, Hlavova E, Kreckova G, et al SNP array and phenotype correlation shows that FLI1 deletion per se is not responsible for thrombocytopenia development in Jacobsen syndrome. Am J Med Genet A. 2012;158A(10):2545-50.

33. Guilherme RS, Kim CA, Alonso LG, Honjo RS, Meloni VA, Christofolini DM, et al. Ring chromosome 10: report on two patients and review of the literature. J Appl Genet. 2013;54(1):35-41.

34. Surace C, Berardinelli F, Masotti A, Roberti MC, Da Sacco L, D'Elia G, et al. Telomere shortening and telomere position effect in mild ring 17 syndrome. Epigenetics \& chromatin. 2014;7(1):1.

35. Guilherme RS, Moyses-Oliveira M, Dantas AG, Meloni VA, Colovati ME, Kulikowski LD, Melaragno MI. Position effect modifying gene expression in a patient with ring chromosome 14. J Appl Genet 2015. [Epub ahead of print].

\section{Submit your next manuscript to BioMed Central and take full advantage of:}

- Convenient online submission

- Thorough peer review

- No space constraints or color figure charges

- Immediate publication on acceptance

- Inclusion in PubMed, CAS, Scopus and Google Scholar

- Research which is freely available for redistribution 